\title{
The Study of Injection Compression Molding of Thin-wall Light-guide Plates with Hemispherical Micro structures
}

\author{
Chuan-zhen Qi \\ College of Mechanical and Electrical Engineering, \\ Beijing University of chemical technology, Beijing, China, \\ 100029. qichuanzhen2006@126.com
}

\section{Jian Zhuang*}

College of Mechanical and Electrical Engineering, Beijing University of chemical technology, Beijing, China, 100029. zhuangjian@mail.buct.edu.cn

\author{
Yong-tao Wang \\ College of Mechanical and Electrical Engineering, \\ Beijing University of chemical technology, Beijing, China, \\ 100029. wangyt@mail.buct.edu.cn

\section{Ya-jun Zhang} \\ College of Mechanical and Electrical Engineering, \\ Beijing University of chemical technology, Beijing, China, \\ 100029. zhyj@mail.buct.edu.cn
}

\begin{abstract}
Light-guide plate (LGP) is a key component of back-light modules in liquid crystal displays; warpage is one of the factors that affect the quality of LGP. Orthogonal simulation and experiment are used in this paper to study the effect of the injection compression molding (ICM) parameters, such as the melt temperature, injection speed, mold temperature, compression distance, and compression speed. Both the simulation and experiment show that the most important factor that affects the products' warpage is melt temperature. And the effect order of the parameters from the simulation analysis is melt temperature, injection speed, mold temperature, compression distance, compression speed, and the effect order from the experiment analysis is same to the simulation analysis. So the experiment results prove the simulation results.
\end{abstract}

Keywords - ICM; Warpage; Light-guide Plates; Orthogonal Method; Parameters

\section{INTRODUCTION}

Liquid crystal displays (LCD) have got a dominant position in the flat display field with the development of the LCD technology, the light guide plates whose function is to redistribute the light source energy over the planar surface is a key component of back-light modules which is an important component of liquid crystal displays ${ }^{[1-3]}$.

The develop trend of light-guide plates is bright, thin and light, and the thin is important and difficult. For injection molding, when $L / t>150$, the products belong to thin-wall products. Here, $L$ means the distance from the main runner to the farthest point of the products and $t$ means the thickness of the products. Warpage is one of the key factors that affect the quality of LGP, and it is mainly caused by the different cooling, orientation and shrinkage. The direct reason is the different shrinkage that caused by different cooling, residual stresses and so on. Other factors that have influence on warpage mainly contain the structure of the mold, the properties of the material, the molding process condition and so on ${ }^{[4-13]}$. In this study, warpage is used to evaluate the quality of the LGP, and also an analysis of the micro structures' filling is done in the experiments. The molded part is a flat LGP, the length, width and thickness of the LGP is $48 \mathrm{~mm}, 36 \mathrm{~mm}$ and $0.3 \mathrm{~mm}$ respectively. The micro structure on the surface of the model is hemispherical with diameter $100 \mathrm{um}$, and the center distance of the micro structures is 200um, as shown in Fig.1.

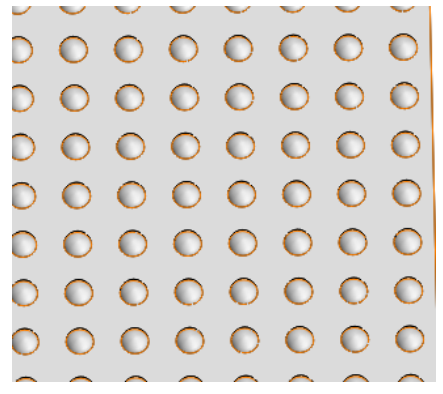

Fig.1 The micro structure

\section{SiMULATION}

\section{A. Simulation Model}

The modeling is shown in Fig.2. Fig.2 (a) shows the 3D model of the product. Fig.2 (b) shows the structure of the filling system which has a fan gate and a trapezoidal runner, the length of the main runner is $60 \mathrm{~mm}$.

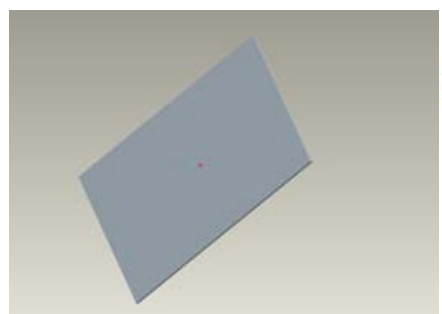

(a)3D model of the products

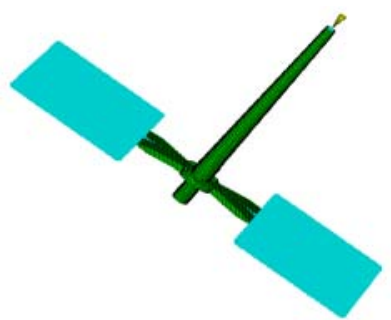

(b)The filling system
Fig.2 Simulation model 


\section{B. Simulation Material}

The Iupilon PC HL4000 is used in the simulation. As the $L / t$ of the model is 187 , the light-guide plates belong to thin-wall product. The main properties and recommend molding process parameters are shown in table 1 .

TABLE 1THE PROPERTIES AND PROCESS PARAMETERS OF THE PC

\begin{tabular}{|c|c|c|}
\hline Parameter & Value & Unit \\
\hline Density & 1.2 & $\mathrm{~g} / \mathrm{cm}^{3}$ \\
\hline Molten index & 63 & $\mathrm{~g} / 10 \mathrm{~min}$ \\
\hline Shrinkage rate & $0.4-0.6$ & $\%$ \\
\hline Dry temperature & $120(4-8 \mathrm{~h})$ & ${ }^{\circ} \mathrm{C}$ \\
\hline Melt temperature & $280-340$ & ${ }^{\circ} \mathrm{C}$ \\
\hline Mold temperature & $80-140$ & ${ }^{\circ} \mathrm{C}$ \\
\hline Injection pressure & $50-150$ & $\mathrm{MPa}$ \\
\hline
\end{tabular}

\section{Selection of Orthogonal Factors}

Melt temperature, mold temperature, injection speed compression distance and compression speed are selected as the orthogonal factors. Table 2 shows the levels selected for each factor.

TABLE 2 EXPERIMENT FACTORS AND LEVELS

\begin{tabular}{|c|c|c|c|c|c|}
\hline \multicolumn{2}{|c|}{ Factor } & \multicolumn{4}{|c|}{ Level } \\
\hline $\begin{array}{c}\text { Factor } \\
\text { code }\end{array}$ & Factor name & 1 & 2 & 3 & 4 \\
\hline A & Melt temperature $\left({ }^{\circ} \mathrm{C}\right)$ & 290 & 300 & 310 & 320 \\
\hline B & Injection speed $(\mathrm{mm} / \mathrm{s})$ & 280 & 300 & 320 & 340 \\
\hline C & Mold temperature $\left({ }^{\circ} \mathrm{C}\right)$ & 110 & 120 & 130 & 140 \\
\hline D & Compression distance $(\mathrm{mm})$ & 0.4 & 0.6 & 0.8 & 1.0 \\
\hline E & Compression speed $(\mathrm{mm} / \mathrm{s})$ & 240 & 280 & 320 & 360 \\
\hline
\end{tabular}

\section{EXPERIMENT}

\section{A. Experiment Equipments}

The Ecopower 55/130 of Battenfeld is used as the injection molding machine, and the injection compression mold is used in the experiment. The equipments are shown in Fig.3.

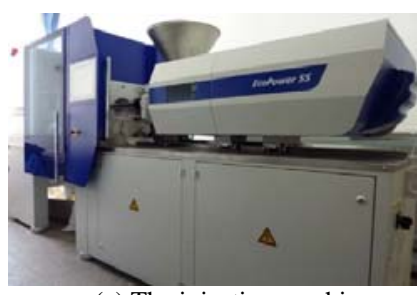

(a) The injection machine

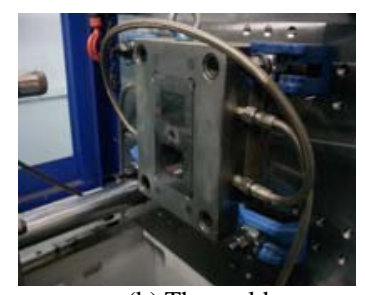

(b) The mold

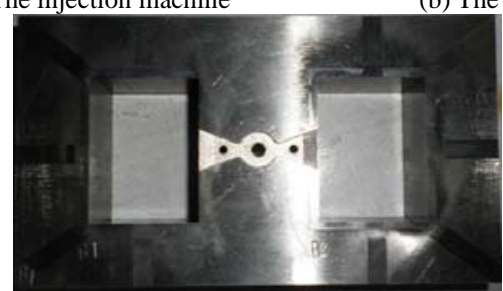

(c) The moving die insert

Fig.3 Experiment equipments

\section{B. Experiments Material and Orthogonal Factors}

Iupilon PC HL-4000 is used for the experiment and the orthogonal factors are same to the simulation.

C. The micro structure of the products

Iupilon PC HL-4000 is used for the experiment and the orthogonal factors are same to the simulation.

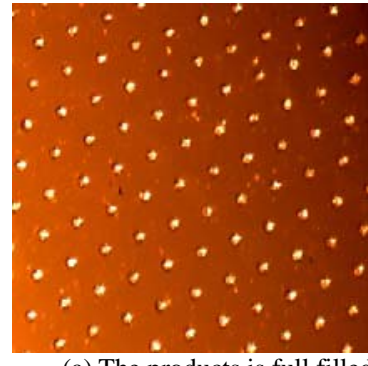

(a) The products is full filled

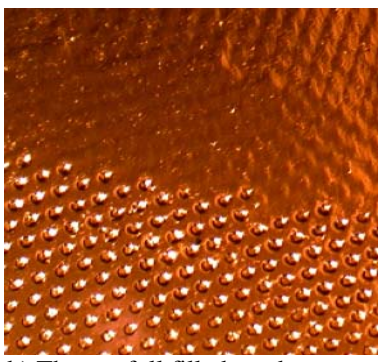

b) The not full filled products
Fig.4 Micro structure of the products

The pictures of the micro structures of the products are shown in Fig.4. Fig.4 (a) shows the filling situation of micro structures whose cavity is fully filled, and the filling is very even. Fig.4 (b) shows the filling situation of micro structures that the cavity is not fully filled. From the picture, the material firstly filled the cavity, and then the micro structures.

\section{RESULTS AND DisCUSSIONS}

Table 3 is the orthogonal experiments and their results of simulation and experiment. Table 4 is the mean value and range of the simulation and experiment.

TABLE 3 RESULTS OF THE ORTHOGONAL SIMULATION AND EXPERIMENT

\begin{tabular}{|c|c|c|c|c|c|c|c|}
\hline Experiment number & A & B & C & D & \multirow{2}{*}{ E } & \multicolumn{2}{|c|}{ Warpage } \\
\cline { 4 - 8 } & 1 & 1 & 1 & 1 & 1 & 0.2396 & 0.272 \\
\hline 2 & 1 & 2 & 2 & 2 & 2 & 0.2375 & 0.251 \\
\hline 3 & 1 & 3 & 3 & 3 & 3 & 0.2384 & 0.267 \\
\hline 4 & 1 & 4 & 4 & 4 & 4 & 0.2377 & 0 \\
\hline
\end{tabular}




\begin{tabular}{|l|l|l|l|l|l|l|l|}
\hline 5 & 2 & 1 & 2 & 3 & 4 & 0.2060 & 0.203 \\
\hline 6 & 2 & 2 & 1 & 4 & 3 & 0.2217 \\
\hline 7 & 2 & 3 & 4 & 1 & 2 & 0.2153 & 0.2267 \\
\hline 8 & 2 & 4 & 3 & 2 & 1 & 0.235 \\
\hline 9 & 3 & 1 & 3 & 4 & 2 & 0.206 & 0.2031 \\
\hline 10 & 3 & 2 & 4 & 3 & 1 & 0.2268 & 0.2312 \\
\hline 11 & 3 & 3 & 1 & 2 & 4 & 0.1743 & 0.168 \\
\hline 12 & 3 & 4 & 2 & 1 & 3 & 3 & 0.1836 \\
\hline 13 & 4 & 1 & 4 & 2 & 3 & 0.1967 \\
\hline 15 & 4 & 3 & 2 & 4 & 1 & 0.191 \\
\hline
\end{tabular}

TABLE 4THE MEAN VALUE AND RANGE OF THE SIMULATION AND EXPERIMENT

\begin{tabular}{|c|c|c|c|c|c|c|c|c|c|c|}
\hline \multirow{2}{*}{ Factor } & \multicolumn{2}{|c|}{$\mathrm{A}$} & \multicolumn{2}{|c|}{ B } & \multicolumn{2}{|c|}{$\mathrm{C}$} & \multicolumn{2}{|c|}{$\mathrm{D}$} & \multicolumn{2}{|c|}{$\mathrm{E}$} \\
\hline & Sim. & Exp. & Sim. & Exp. & Sim. & Exp. & Sim. & Exp. & Sim. & Exp. \\
\hline Mean1 & 0.238 & 0.266 & 0.205 & 0.211 & 0.222 & 0.240 & 0.217 & 0.231 & 0.217 & 0.224 \\
\hline Mean2 & 0.217 & 0.224 & 0.211 & 0.216 & 0.218 & 0.223 & 0.216 & 0.223 & 0.214 & 0.223 \\
\hline Mean3 & 0.215 & 0.221 & 0.219 & 0.230 & 0.212 & 0.221 & 0.212 & 0.221 & 0.216 & 0.228 \\
\hline Mean4 & 0.189 & 0.189 & 0.224 & 0.242 & 0.208 & 0.216 & 0.214 & 0.225 & 0.214 & 0.224 \\
\hline Range & 0.049 & 0.077 & 0.019 & 0.031 & 0.014 & 0.024 & 0.005 & 0.010 & 0.003 & 0.005 \\
\hline
\end{tabular}

According to the range of the factors, the most important factor that affects the product's warpage is melt temperature and the effect order of the parameters from the simulation and experiment analysis is same.
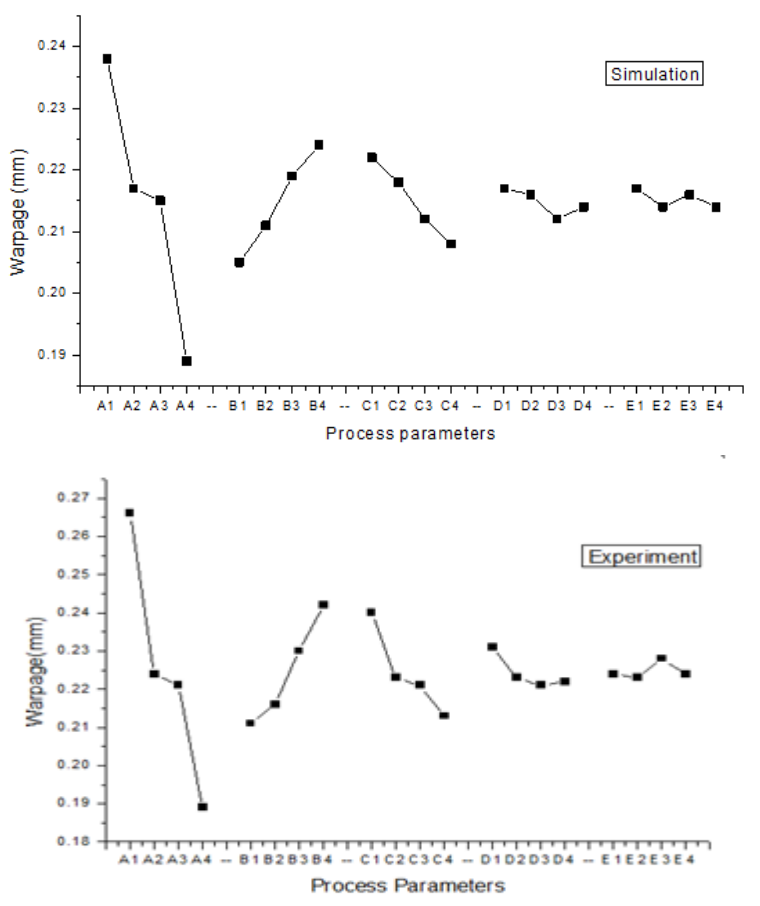

Fig. 5 The effect of the five factors on warpage
Fig. 5 shows the effect of all the five factors on the warpage of the light-guide plate. The effects of the parameters on warpage are listed as follows:

\section{1) The effect of the melt temperature}

It can be seen from the Fig. 5 that with the increasing of the melt temperature, the warpage decreases clearly, it is mainly because of the good flow state that caused by the higher melt temperature, and the good flow state can reduce the shear stress as the melt flow and the internal stress caused by the uneven compression pressure. The warpage is mainly caused by the internal stress and the uneven shrinkage. So increasing the melt temperature to a certain extent can help to reduce the warpage of the products.

\section{2) The effect of the injection speed}

It can be seen from the Fig.5 that the warpage will increase as the increasing of the injection speed, it is mainly because that the thickness of the core is very small. During the process of injection, it may cause jet phenomenon which may cause the uneven distribution of the material before compression and the melt collision during the compression when the injection speed increases. So it is likely to cause internal stress. Therefore the greater the injection speed, the greater the warpage.

\section{3) The effect of the mold temperature}

The effect of the mold temperature on the warpage is similar with the melt temperature; the warpage will decrease as the increasing of mold temperature. It is mainly because that the melt will maintain a good flow state in a certain time which is good to decrease the internal stress of the product 
and the feeding during the compression process.

\section{4) The effect of the other parameters}

The compression distance and compression speed have a little effect on the warpage. It can be seen from the Fig.5, the best compression distance is $0.8 \mathrm{~mm}$ which is about 2.5 times of the thickness of the products, the change of the compression distance increase the warpage. For compression speed, there is no obvious effect pattern and the effect is not obvious. It is mainly because that the thickness of the products is very small and the compression distance is very small too. From Fig.5, the best compression speed is $280 \mathrm{~mm} / \mathrm{s}$.

\section{CONCLUSIONS}

The conclusion of this paper is given as follows:

(1) The main factor that affects the warpage of the products during the injection compression process is the melt temperature, the effect order of the parameters from simulation and experiment is melt temperature, injection speed, mold temperat- ure, compression distance, and compression speed.

(2) The best set of process parameter is A4B1 C4D3E2 with minimum warpage.

(3) The material firstly filled the cavity, and then the micro structures.

(4) In actual production, the melt temperature and the mold temperature should be increased in the allow range to get good quality for thin wall products.

\section{REFERENCE}

[1] Cheng-Huan Chen, Po-Chou Chen, Chien-Chuan Chen. High extinction ratio polarized light guide with layered cross stacking nanostructure [J]. Microelectronic Engineering, 2009(86):1107-1110.

[2] Jong Sun Kim, Dong Sung Kim, Jeong Jin Kang, Jong Deok Kim, Chul Jin Hwang. Replication and Comparison of Concave and Convex Microlens Arrays of Light Guide Plate for Liquid Crystal Display in
Injection Molding [J]. Polymer Engineering and Science -2010: 1696-1704.

[3] T.H.Lin,A.I.Isayev, M.Mehranpour. Luminance of Injection-Molded V-Groove Light Guide Plates [J]. Polymer Engineering and Science-2008: 1615-1623.

[4] Ming-Shyan Huang, Chin-Feng Chung. Injection Molding and Injection Compression Molding of Thin-Walled Light-Guided Plates with V-Grooved Microfeatures [J]. Journal of Applied Polymer Science, 2011(121):1151-1159.

[5] Yung-Kang Shen, Chih-Yuan Chang, Yu-Sheng Shen, Sung-Chih Hsu, Ming-Wei Wu.Analysis for micro structure of microlens arrays on micro-injection molding by numerical simulation [J]. International Communications in Heat and Mass Transfer, 2008(35):723-727.

[6] Wen-Bin Young. Effect of process parameters on injection compression molding of pickup lens [J]. Applied Mathematical Modeling, 2005(29):955-971.

[7] Cheng-Hsien Wu and Yi-Li Su. Optimization of wedge-shaped parts for, injection molding and injection compression molding [J].Int. Comm. Heat Mass Transfer, 2003:215-224.

[8] Hajime Suzuki, Tetsuo Takayma, Hiroshi Ito. Replication behavior for micro surface features with high aspect ratio and structure development in injection compression molding [J]. Advanced Materials Development and Performance, 2012(6):563-569.

[9] Wen-Bin Young. Effect of process parameters on injection compression molding of pickup lens [J]. Applied Mathematical Modeling, 2005(29):955-971.

[10] Cheng-Hsien Wu and Yi-Li Su. Optimization of wedge-shaped parts for, injection molding and injection compression molding [J].Int. Comm. Heat Mass Transfer, 2003:215-224.

[11] K.K. Kabanemi, H, Vaillancourt, H, Wang, G. Salloum. Residual stresses, shrinkage, and warpage of complex injection molded products: Numerical simulation and experimental validation [J]. Polym. Eng. Sci. 1998.

[12] Xu Fei, Wang kejian, Yan Yue. Simulation Analysis of Injection Compression Molding Thin-Wall Optical Plastic Part [J]. Plastic,2010(39):115-119.

[13] Y.K. Shen, W.Y. Wu, S.Y. Yang, H.M. Jian, C-C.A. Chen. Study on numerical simulation and experiment of light-guide plate in injection molding [J]. Journal of Reinforced Plastics and Composites 2004 (23) :1187-1206. 